\title{
Scholarly Societies in the Age of COVID
}

Laura Brown

Roger C. Schonfeld 


\section{ITHAKA S+R}

Ithaka S+R provides research and strategic guidance to help the academic and cultural communities serve the public good and navigate economic, demographic, and technological change. Ithaka S+R is part of ITHAKA, a not-for-profit organization that works to advance and preserve knowledge and to improve teaching and learning through the use of digital technologies. Artstor, J STOR, and Portico are also part of ITHAKA.

Copyright 2020 ITHAKA. This work is licensed under a Creative Commons Attribution 4.0 International License. To view a copy of the license, please see https:// creativecommons.org/licenses/by/4.0/.

ITHAKA is interested in disseminating this brief as widely as possible. Please contact us with any questions about using the report: research@ithaka.org. 
As membership organizations with revenues typically derived from a combination of publications, meetings, and dues, scholarly societies have faced distinctive challenges, as well as opportunities, in navigating the pandemic. To explore these, we spoke with chief executives and chief publishing officers at 12 large and small societies, some focused on the humanities and social sciences, others on the STEM fields. We were interested in how the various sources of activity and value for scholarly societies were being impacted by the pandemic, how they were coping, and what they expected to see in the future. We were a full six months into the pandemic when we conducted these interviews so there was evidence to bring to the question of longer term impacts. As one director put it: "We're all waking up to the realization that this is not just a short term emergency." ${ }^{\prime 1}$

\section{Coping with the Pandemic}

Every society director we spoke with was pleased with the way their organization had made the transition to a virtual environment. Some saw the virtual workplace as a temporary change they hoped to weather; others as a transformation to embrace. On the positive side, we heard about recruiting opportunities ("work from anywhere opens up talent from everywhere"), possible savings in rent that were being evaluated, and the potential to learn new skills ("My staff quickly became experts in how to run a good virtual meeting"). One director put it this way: "We went from an organization that allowed some telework, to one that may never go back. We intend to reimagine how we want to work together remotely. We had no full-time telework option before the pandemic, but we're likely to be more open to that in the future. People really stepped up and worked effectively and we saw virtually no productivity changes. We had a lot of Zoom fatigue at the beginning, but we're figuring out how to make that better."

But there were also concerns about the long-term effects of the virtual workplace. We heard how difficult it is to foster trust and build real community remotely, especially for new employees. Some questioned productivity now that the bloom of a successful pivot has worn off. One director mentioned that they had been working partly remotely for many months prior to the pandemic because of an office renovation, so they knew something about doing this. "The disadvantage for us is that everyone was already tired of remote." The switch to virtual also raised the question of whether directors were sufficiently equipped to lead in this new remote environment. "The pandemic has raised big management questions. We need management strategies and structures to deal with this. How do you manage a staff of 30 and a membership organization under these circumstances? Staff concerns are what keep me up at night."

\section{The Financial Picture}

Six months into the pandemic, the main theme we heard was uncertainty. While 2020 revenues were not as bad as anticipated, especially as some societies got PPP loans and journal subscriptions were locked in early before the impact of COVID, it was hard for directors to budget for 2021. We heard a few upbeat forecasts, especially from societies that enjoyed revenue

\footnotetext{
${ }^{1}$ Our thanks to Joseph Esposito and Kimberly Lutz for comments on an earlier version of this paper.
} 
guarantees from their publishing partners, but most directors were planning for a shortfall in at least one, and possibly all three of what are typically their main sources of revenue-

conferences, membership, and publishing - coupled with compensatory cost trimming and in some cases a dip into reserves. Worst case scenarios were in the 20-25 percent range. "Our fiscal year began in J uly. We're expecting a shortage in dues, a shortage in sales, and we're going to a virtual-only meeting next April so we'll have a reduced revenue expectation from that."

We asked smaller societies in particular if they thought they would be able to survive these headwinds. Most felt that they could, although there was more concern among those in the humanities and those that depended heavily on meeting revenues. One director at a humanities society, while confident of his own program, said "When I looked around the room at an ACLS meeting, it struck me that there are not going to be 75 societies in the next 10 years. I want to be one that is left!"

Financial uncertainty varied considerably based on the relative mix of reliance on conference, publishing, and membership revenues. We take a deeper dive into all three of these now.

\section{Conferences and Events}

“The biggest thing we're wrestling with is in-person events: both professional development events and the annual convention. We have to prepare for worst case scenarios, but we've also seen some encouraging trends."

\section{Immediate impact}

All societies pivoted to virtual meeting formats and suffered a financial hit as a result. The extent of the shortfall, and its implication for the financial health of the organization, varied depending on the size of the meeting, whether it typically generated a surplus, what each society decided to charge for virtual participation, what it cost to run a successful virtual event, and to what extent they were able to avoid costly penalties for pre-booked venues that were no longer viable. We heard some very big numbers in terms of losses-for some over a million dollars.

Much depended on the extent of reliance on meeting revenues. Societies that typically ran their annual meeting as a cost-based event were less worried. "We lost some revenue, but also didn't spend as much. It was not the same kind of big hit to us because we don't depend on the meeting as a significant part of our revenue." But for others, especially those with large meetings that typically generate annual surpluses, the pivot to virtual created a big hole. One director told us "Our annual meeting generates three quarters of a million in surplus and represents almost 30 percent of our revenues. That surplus allows us to engage in services without revenue-fellowships, awards, outreach and engagement, special projects, travel stipends, marketing, and advocacy and professional development. We won't see that crosssubsidization this year." 
Many societies had pre-booked venues. How they navigated these commitments made a big difference in how they fared. The lucky ones were able to get out of their contracts because of the pandemic. "It could have been worse," one director told us. "Our conference was held in a state where the governor prohibited large gatherings, allowing the force majeure to kick in. Otherwise we would have been on the hook for \$1.3 million. That would have been devastating." Other directors said that they were able to renegotiate with hotels to transfer their commitment to a future year, thus avoiding the penalty, although they worried about the potential for this locked-in space commitment given that future in-person meetings were likely to be smaller.

And then there was the question of participation and what to charge. As societies transitioned their meetings into virtual formats, we heard many interesting data points in their attempt to develop a monetization strategy on the fly. Some societies charged nothing, saw large increases in participation and an opportunity to expand the size and quality of their marketing lists as a result, yet worried about the precedent they were setting. Others charged the same amount as for in-person, but had 20-40 percent fewer participants. Still others cut the price in half and still had a steep decline in participation, or hadn't decided yet what to charge for their upcoming fall or early winter annual meeting. Many struggled to balance the expectation that "online should be free" with the reality that it is costly to put on a good virtual event. No best practices emerged. It would be instructive to compile these data at scale once we are through a year of experimentation to see if best practices emerge.

\section{Thoughts about the future}

Meetings and events play a central role for societies. The privilege of being able to present at annual and regional conferences is in many cases a key benefit of membership, as is the availability of registration discounts. Meetings offer critical networking and professional development opportunities. Looking ahead from the scramble to put on an annual meeting this year to the possibilities for future events, there were a number of encouraging and worrisome trends cited. How directors navigate these will play a major role in the future direction of their societies.

In-person attendance at events is likely to drop off, even when COVID restrictions ease. With few exceptions, directors worried that in-person annual meetings were likely to be smaller in the future. This trend line was already evident for many societies, but with the predicted reduction in professional development budgets and cutbacks in faculty positions over the next few years, the trend is likely to accelerate. Lower attendance could also mean lower submissions to the conference, and that would have a knock-on effect on membership. "Already submissions to present a paper are only a quarter of what we saw last year. The annual meeting is a big driver of membership. The impact of weak attendance can ripple through for years."

Virtual meetings open new possibilities. Directors were particularly excited about the ways their virtual meeting enabled more early career academics and international members to attend. 'We had participants in our conference from countries we couldn't even imagine. Even when we can go back to in-person, we're thinking about a hybrid congress for the future." In 
addition to the attraction of hybrid solutions, which many directors are leaning towards, regional and smaller theme-focused meetings also hold promise; they cost less, can address regional and shared issues, and offer opportunities for more affinity-based networking and professional development. Providing, virtually, the intangible benefits of getting together at meetings, especially the chance to catch up with colleagues and make new connections, is perhaps the biggest challenge directors are struggling to reimagine.

Societies are looking for ways to maintain exhibitor revenues. We were not able to determine a trend line for exhibitor participation in the raft of virtual meetings, but it would be good to gather data over the year and see if patterns emerge. There is an obvious risk that the unbundling of the program from the exhibitions will accelerate during this period of disruption. We definitely heard concern that meeting income stream would dwindle, but perhaps this is another opportunity for reinvention. Publishers and other vendors value the opportunity to reach disciplinary audiences. What new opportunities can be created in a virtual environment to make their products and services more visible in ways that participants value?

Better technology solutions and staff expertise are needed to run virtual meetings. Some directors are looking into new platforms with more capability to host their online meetings. Others talked about the challenge of running hundreds of breakout sessions. "If we did it well, our net could be higher." And the challenges were not just seen as technical; they include finding creative ways to foster interaction, vary pace, minimize burnout from staring at a screen all day, enable a social element, and improve accessibility. One director put it this way: "The bar is going to be set higher on what happens at annual meetings. Production values are going nowhere but up." Next year, it would be interesting to survey societies about the approaches they took and what worked on both the technology and skills training fronts.

Virtual creates potential for audience expansion - within the discipline, beyond the discipline, and beyond the academy. The number of webinars sponsored by societies exploded in the last six months, as did the size and variety of the audiences they attracted. We heard from many directors that they were amazed by the kind of attendance they were seeing. One told us, "We had a free webinar that attracted, 1400 people. If you told me that we could have that many people attending a webinar where I interview a couple of historians, I would say why?? We've done things online before but compare this to our YouTube videos that get a couple dozen views." Others talked about the valuable business intelligence that could be gathered from the wide range of participation, or the way they were trying to harness this attention to build membership leads. "We recently had a webinar on narrative medicine with 1,000+attendeeswe never would have reached an audience that size in the summer to learn about a topic like this! We're now mining the attendee list to generate member prospects both within and outside the discipline." Webinars were also seen as a great mission fit to expand public knowledge of the discipline. Are these audience spikes a temporary COVID-related benefit because more people are stuck at home and looking for ways to connect, or do they represent a real opportunity to deliver new services? And is there any way to charge for events like these? We heard of one society that was investigating sponsorships for its webinars, and another that was trying to secure foundation support. No one mentioned charging. 


\section{Membership}

"All of our conversations end up back in this place of how to create benefits that maintain or grow our member base. We need help thinking about this!"

Most directors are worried about a falloff in membership over the next few years, for a variety of reasons. The poor attendance at spring and summer meetings was one harbinger of tough times ahead. Anticipated budget cutbacks in higher education was another. One director summed it up this way: "It could be years before the university sector recovers. Faculty layoffs. Departmental budget cuts. Will our members no longer be able to afford membership?"

\section{Immediate impact}

Humanities societies are most greatly affected in the near term. With universities cutting adjunct professors and other contract teaching positions in the humanities as one of their earliest cost saving measures, humanities society directors are bracing for substantial cuts in membership. With fewer predicted job losses among their members, societies in science fields are not anticipating substantial resulting membership losses, although they are carefully monitoring the value of their membership offering especially in cases where a substantial part of the value has been in discounted meeting participation rates.

\section{Thoughts about the future}

We heard a number of interesting suggestions about how to rethink member benefits in a time when faculty are losing financial support for their professional development, and competition for their engaged attention is heightened by the pandemic. People are professionally and personally overwhelmed. How long this will continue is hard to predict. Here are a few of the strategies societies are pursuing to strengthen connection to their members and grow their pipeline of prospects. Many of them are not new, but they have taken on added urgency.

Building onramps through free and limited services. We heard from several societies that they are piloting affiliate or loyalty membership programs that cost nothing, or a smaller set of services they can charge less for, and experimenting with how to make the offering attractive enough to grow participation while reserving key benefits, such as delivering a paper at the annual meeting, to full paid membership. Setting these tiers at the right level to ensure that existing membership isn't cannibalized was a concern, but the pandemic seems to be putting a premium on experimentation.

Tying together publishing and membership benefits. One chief publishing officer at a society that has invested in a chief engagement officer mentioned an intriguing experimental program: "If you publish OA with us, you automatically become a member for a year." She saw this as not just a publishing initiative, but a way to build community. In this model, publishing does its job to attract potential members, and it is then up to the society to strengthen the connection to other member benefits." The program is still very early days, but definitely worth watching. 
Building membership through collaboration. Directors reinforced that while societies compete with each other, some were also thinking about ways to foster cooperative agreements that might lead to new membership benefits and pathways to expansion, especially given the interdisciplinarity of the academy which argues for new ways to support member interests across fields. One director said he was looking to create a network of like-minded organizations, and would consider mergers as long as they were with an equal and complementary partner. Others mentioned shared meetings as an area for exploration, as well as shared training programs and definitions of standards and norms. But there was the lurking worry about competition for member dollars and attention (what one director called the holy grail of engaged members, which is always a goal but particularly challenging given the amount of distraction introduced by the pandemic). Some societies are also side-eyeing their samediscipline peers in other parts of the world, for example in J apan, China, Australia, the United Kingdom, and Germany. Given the shift to pervasive global distribution of publications and now to virtual conferences that, after taking time zones into account, can be attended just as easily by a scholar regardless of location, the national distinctions raise questions about whether societies in other countries are allies or competitors. One executive grappling with this question noted, 'We're kind of frenemies. At what point do you cannibalize authors, contributors, sponsors, and members?"

Need for a different mindset. Several directors told us that the pandemic introduced the need for a different mindset about members. One director put it this way: "We need to intentionally disrupt ourselves the way the pandemic is disrupting our expectations. I'm trying to think of my members as customers. If I can't provide the goods and services that they need, it's illogical to charge for membership. This is rhetorical, but it helps me think differently."

\section{Publishing}

"On the publishing side, not much has changed. The whole nature of the work is far more possible to do virtually."

'We have a guarantee for the next several years, but we'll need to think of new strategies for the longer term. Do we charge more for processing charges? Should we charge submission fees? Shift the flagships to online only for our members? Launch a couple new big OA journals? Launch a Books program?”

\section{Immediate impact}

There was little evidence of immediate impacts from the pandemic on journal publishing operations. Submissions seem to have held steady over the last six months, and in some cases were up, although there was recognition that authors with school age children were finding it harder to set aside time to write, and some authors who work in labs encountered delays in completing their research. Usage doesn't appear to have suffered either. The kind of changes we 
saw with university presses converting to better digital workflows was not evident here; ${ }^{2}$ most societies already had implemented digital processes. And no one reported delays in their publishing cycle.

We wondered if the pandemic created more pressure for societies to convert to open access models. While many made some of their content temporarily open, especially the COVIDrelated material they published ('We're 24/ 7 COVID, all freely available to everybody: research articles, advocacy, wellness information, podcasts and webinars”), we didn't hear anything beyond the usual mix of inducements and hesitations to move to OA. The directors we spoke with were all over the map in trying to navigate these variables and the constituencies they impact, with STEM publishers feeling more urgency to respond to calls for open science and funder demands. "We're getting pressure from the industry and funders, but not from our authors and members," one director told us. Plans to launch new OA journals, or transition existing journals to OA models seemed part of the natural evolution of thinking rather than a response to the pandemic. Many societies were happy with their current mix of subscription, hybrid, and fully open journals, and weighing an evolutionary path that protected their sustainability.

On the financial side, presses with book programs expected to take a temporary hit of as much as 20-30 percent in their book revenues because of library cutbacks, but, since books are not a significant factor in most society publishing, the impact was likely to be negligible. Expectations for journal revenues were harder to predict. While many said they were "hoping for the best but planning for the worst," there was also an upbeat contingent, especially among smaller societies, who thought they would be in good shape because they were hearing encouraging signs from their publishing partners, or believed that the reputation of their journals would insulate them from cancellations, or, perhaps most often mentioned by those who contracted for publishing services, they had negotiated guarantees that protected them in a downturn. We heard a number of "phews" in this vein, but also concern about the impact this could have on their business partners. "We made the move just in time. We're guaranteed revenue and have an upside if they do even better. We're not anticipating a hit at all. Once again the journals are saving the day, but we recognize this puts the burden on our contract partner." It would be interesting to revisit this question from the point of view of publishing service providers once we have the evidence from the 2021 subscription season.

\section{Thoughts about the future}

This question of whether to stay independent or sign with a commercial partner came up several times. It is very much on the mind of smaller and mid-sized societies who cite the advantage of scale and expertise. Nothing new here; this question has been weighing on societies for some time. But the prospect of a lengthy economic downturn, combined with the lure of financial stability, the desire to free up internal resources to do new things, and especially the need to get

\footnotetext{
${ }^{2}$ Laura Brown, "University Presses in the Age of COVID-19: How Press Directors are Navigating the Challenges of the Pandemic," Ithaka S+R, June 24, 2020, https://sr.ithaka.org/blog/university-presses-in-the-age-of-covid-19/.
} 
a seat at the table for transformative deals, is upping the pressure to consider signing with a partner. 'We just don't have the expertise for these deals, and being independent, it's hard to get attention because commercial publishers are the priority."

While some publishers are just hunkering down to weather the storm, many are looking to take advantage of this crisis to innovate on a number of fronts. Here are some of the things they are considering:

Product diversification. In addition to product extensions, directors are exploring entirely new lines. The launch of an online posters service was one such idea ("it fulfills a really different need than a journal article"); another was developing a discipline-based discovery portal for all the content available from publishers in the discipline. Further afield, we heard about one society's development of a program of traveling exhibitions hosted by as many as 50 museum partners on major issues such as race, displacement, and climate change. And more ambitious still, we learned of a society's plan to build its own cultural center/ museum which could be used for events, lectures, and exhibitions. It was interesting that no one mentioned data services as an area to explore.

Product consolidation Some societies have an array of publications and products that result in significant transaction costs and other forms of overhead in order to sell and buy. One interviewee was hoping to address this dilemma: "Our products are all interrelated for teaching and research. Are there ways we can bring them together into one ecosystem/ bundle?" This is more of a dream at this point, but it does recognize the approach to product development that internet companies are taking, even as it is out of sync with the demand for micro slices and choice on the part of libraries. Although few if any societies have a sufficient array of products to populate a bundle in their fields, some might envision fruitful partnerships with their "frenemies," so it will be interesting to watch this space.

New markets. Several directors talked of wanting to explore the creation of a general interest magazine to translate their field for professional and general audiences. One society had already created such a resource that was freely available, and was now experimenting with Google Ads to sustain it. Education and professional development were potential expansion markets for some societies. One director told us they were in the process of thinking about investing in an LMS platform to be used as a virtual classroom for webinars, online workshops, and training. Another was looking at ways to adapt their research products to educational uses. Corporate sector strategic alliances were a new avenue for some societies to reach professional markets, with the potential to secure sponsorship for publications such as whitepapers and events.

But innovation is hard. And it can be especially hard for societies trying to support member expectations and navigate governance issues. "Our members are interested in products that are the best of show: best journal in the field, best education product. Their reluctance to do anything that isn't first rate leaves us in the position of needing to invent new revenue streams, but how to do that is the challenge. It's hard to invent when it has to be first rate. It's also hard to develop long range innovations when there is regular turnover of presidents, chairs of our board of regents, board membership, and chapters." Even when a society recognizes the need to 
develop new products and services, reaches out to understand the emerging needs of its members, studies the innovation in adjacent fields and industries, and has the continuity of support from its board, developing revenue-generating products can be especially challenging. "All we're doing now is additional work that is freely available." And transformation comes with cost, especially for organizations that haven't changed much, which is the case for most societies.

\section{Final Thoughts}

We ended our conversations about the impact of the pandemic on societies with this question to the directors we spoke with: What keeps you up at night and what are you most excited about? Many of the concerns and hopes they raised have been touched on above, but a few additional themes emerged which we list here. We leave you with these worries, and one optimistic comment that seemed to summarize many we heard.

- The war on science. 'I'm worried about the continued war on science if this administration continues. The funding hasn't been that bad so far, but immigration is a huge problem (for instance the H1Bs executive order), and who knows what will happen to government funding in the next four years."

- Plan S/government policy. "Will US funding agencies mimic Europe? I worry that people behind Plan S won't be happy until everything is freely available. They don't care how societies will sustain themselves."

- Impact on the field itself. "I fear that higher education goes into austerity mode and discounts the value of our field so greatly that we see a loss of degree programs and tenure lines."

- Despite all of the challenges, the future of scholarly publishing can be bright. "The spoils are going to go to whoever is most adaptable. It's not just open access. We need to watch closely how scholars' productivity and preeminence is measured. How do you adapt to that? Organizations that have ears to the ground and can adapt best are going to succeed." 